\title{
Monarticular septic arthritis of the sternoclavicular joint
}

\section{Sir}

Swelling of the sternoclavicular joint may be seen in rheumatoid arthritis, ankylosing spondylitis, osteoarthritis, gout, rheumatic fever or Tietzes' syndrome, but infective arthritis is rare.

Septic arthritis of the sternoclavicular joint was first described by Vogelius in 1896 secondary to suppurative pneumococcal chest infection (Vogelius, 1896), and in the pre-antibiotic era, 14 cases appeared in the literature (Bulkey, 1914) which was reviewed by Taleisnik et al. (1962) with the addition of one case.

Since the advent of antibiotic therapy sporadic cases of acute septic arthritis have been reported caused by Staphylococcus aureus (Linscheid et al., 1961) and salmonella species (David \& Black, 1960). The illness presents as an acute septic arthritis with a high swinging temperature, systemic upset, and a hot, swollen, tender joint with a raised white cell count and ESR. We have seen one such case caused by Staphylococcus aureus which responded readily to open drainage and antibiotic therapy. Radiographs and tomograms were normal.

Of particular interest are two cases of gram negative septic arthritis of the sternoclavicular joint, one caused by Pseudomonas aeruginosa, the other by Klebsiella. Pseudomonas septic arthritis of the sternoclavicular joint was first described by Goldin et al. (1973) in heroin users and 20 further cases have subsequently been reported.

Our findings agree with other authors in that the disease is chronic with a long prodromal period, no systemic upset, local swelling but minimal tenderness occurring in the drug abuser or vagrant element of society. Plain radiographs are abnormal in $50 \%$ of cases and tomograms show bony erosion in every case. Blood investigations are normal. Needle aspiration will not provide a bacteriological answer but arthrotomy does in a high percentage of cases. Culture for pseudomonas and Klebsiella should be requested specifically. Good results are achieved by arthrotomy, drainage, debridement, antibiotic therapy and healing by secondary intention. Occasionally, excision of the medial end of the clavicle may be necessary, if infected, but this did not prove necessary in either of our patients. It may be that the non-infective subacute arthritis described by Bremner (1959) is of a similar aetiology.

The differential diagnosis should include chronic sclerosing osteomyelitis (Garre, 1893) and primary chronic sclerosing osteomyelitis first described by Hardmeier et al. (1974) to differentiate it from the disease described by Garre (1893).

\section{REFERENCES}

Bremner R. A. (1959) Mon-articular non-infective subacute arthritis of the sternoclavicular joint. Fournal of Bone and foint Surgery 41, 749-53.

Bulkey K. (1914) Pneumococcic arthritis. Annals of Surgery 59, 71-100, Jan. 1914.

David J. R. \& Black R. L. Salmonella arthritis. Medicine (Baltimore). Vol. 39, 385-403, Sept. 1960.

Garre C. (1893) Ueberbesondere Formen and Folgezustände der akuten infektuosen Osteomyelitis. Beiträge zur Klinik und Chirurgie 10, 257-65.

Goldin R. H., Chow A. W. \& Edwards J. E. (1973) Sternoclavicular septic arthritis in heroin users. New England fournal of Medicine 289, 516-8.

Hardmeier T., Uehlinger E. \& Muggli A. (1974) Primar chronische sklerosierende Osteomyelitis. Verhandlungen der Deutschen Gesellschaft für Pathologie 58, 474-7. 
Linscheid R. L., Kelly P. J., Martin W. J. \& Fontana R. S. (1961) Mon-articular bacterial arthritis of the sterno-clavicular joint. Fournal of the American Medical Association 178, 421-2.

Taleisnik J., Paterson L. F. A. \& Martin W. J. (1962) Mon-articular bacterial arthritis of the sterno-clavicular joint due to diplococcus pneumoniae. Report of a case and review of the literature. Mayo Clinical Procedures 37, 582-5.

Vogelius (1896) Archives de Médecine Expérimentale et d'Anatomie et Pathologie, viii.

\section{J. TAYLOR \& G. J. BELHAM}

Orthopaedic Department, Central Middlesex

Hospital, London, England 